\title{
Relevance of gap junctions and large pore channels in traumatic brain injury
}

\author{
Nora Prochnow* \\ Department of Neuroanatomy and Molecular Brain Research, Ruhr-University Bochum, Bochum, Germany
}

Edited by:

Georg Zoidl, York University, Canada

Reviewed by:

Xavier Gasull, University of

Barcelona, Spain

Nicolas Froger, Institut de la Vision,

France

\section{*Correspondence:}

Nora Prochnow, Department of

Neuroanatomy and Molecular Brain

Research, Medical Faculty,

Ruhr-University Bochum, MA6/159

Universitätsstr. 150, D-44780

Bochum, Germany

e-mail: nora.prochnow@rub.de
In case of traumatic brain injury (TBI), occurrence of central nervous tissue damage is frequently aligned with local modulations of neuronal and glial gap junction channel expression levels. The degree of gap junctional protein expression and intercellular coupling efficiency, as well as hemichannel function has substantially impact on the course of trauma recovery and outcome. During TBI, gap junctions are especially involved in the intercellular molecule trafficking on repair of blood vessels and the regulation of vasomotor tone. Furthermore, gliosis and astrocytic swelling due to mechanical strain injury point out the consequences of derailed gap junction communication. This review addresses the outstanding role of gap junction channels in TBI pathophysiology and links the current state of results to applied clinical procedures as well as perspectives in acute and long-term treatment options.

Keywords: traumatic brain injury, Connexin, Pannexin, penumbra, glial scar, astrocytes, blast, excitotoxicity

\section{INTRODUCTION}

Traumatic brain injury (TBI) is defined as a severe intracranial injury due to external impact force. Insurance industry and many health care providers treat TBI as an "event." Once treated with a brief period of rehabilitation, the perception exists that patients with a TBI require little further treatment and face no lasting effects on the central nervous system or other organ systems ( $\mathrm{Lu}$ et al., 2013; Selvarajah et al., 2013). As a chronic disease TBI meets the World Health Organization definition as having one or more of the following characteristics: it is permanent, caused by nonreversible pathological alterations, requires special training of the patient for rehabilitation, and/or may require a long-period of observation, supervision, or care. TBI increases long-term mortality and reduces life expectancy. It is associated with increased incidences of seizures, sleep disorders, neurodegenerative diseases, neuroendocrine dysregulation, and psychiatric diseases that may arise and/or persist for months to years post-injury.

One of the major factors in cellular pathophysiology, leading to long-lasting effects in TBI patients, is based on the interruption of gap junction connectivity of the neuro-glial network and mechanically induced opening of large pore channel conductances due to the traumatic event (Avila et al., 2011).

Gap junctions enable neurons and glial cells to communicate by exchange of ions and small molecules via intercellularly connected, adjacent channel proteins (Prochnow and Dermietzel, 2008; Eugenin et al., 2012). Each of these channels is consisting of six subunits of integral membrane proteins, termed Connexins (Cxs) (Figure 1). In mice and humans, Connexins are encoded by a family with 20 and 21 genes, respectively (Berthoud and Beyer, 2009). In the CNS of rodents, the majority of Connexin isoforms $(n=11)$ are expressed by glial cells (Prochnow and Dermietzel, 2008; Giaume and Theis, 2010; Mika and Prochnow, 2012; Rash et al., 2012). Among others, Cx36 gives rise to the main neuronal gap junction channel forming protein (Belluardo et al.,
2000; Venance et al., 2000; Rash et al., 2012; Belousov and Fontes, 2013). Connexins can also be expressed as unopposed hemichannels in cells of the CNS. In this context, different types of Cxs form hemichannels (Schock et al., 2008; Giaume and Theis, 2010; Saez et al., 2010).

Additionally, a vertebrate protein family, Pannexins (Pxs) (Figure 1), with a strong homology to Innexins (Figure 1) has been described (Panchin et al., 2000; Baranova et al., 2004; Panchin, 2005). Innexins are the gap junction forming proteins in insects. Recent findings reveal that Px1, expressed on neurons and glial cells (Thompson et al., 2008; Macvicar and Thompson, 2010; Bargiotas et al., 2011; Prochnow et al., 2012), operates as a unique large pore channel instead of forming gap junctions (Bao et al., 2004; Locovei et al., 2006a,b; Pelegrin and Surprenant, 2006, 2007; Romanov et al., 2007; Zoidl et al., 2007).

Here we discuss the role, function, and regulation of Connexin-based gap junctions and hemichannels as well as Pannexin1 large pore channels (summarized in Table 1) in the context of concomitant network (dys-)regulation and proinflammatory effects according to TBI. Furthermore, the latter proteins will be focused with regard to experimental and clinical treatment options which might influence the long-term outcome in TBI patients in future times.

\section{THE ROLE OF GAP JUNCTIONS AND CONNEXIN HEMICHANNELS DURING CNS INJURY NEURONAL CONNEXINS}

Electrical synapses based on Cx36/Cx35gap junctional contacts are common for dendro-dendritic as well as dendro-somatic neuronal connections and contacts between axon terminals (HamzeiSichani et al., 2007). In the mammalian central nervous system, Cx36 is expressed by neurons in a dynamic manner: the coupling of neurons by gap junctions and the expression of Cx36 transiently increase during early postnatal development and take 


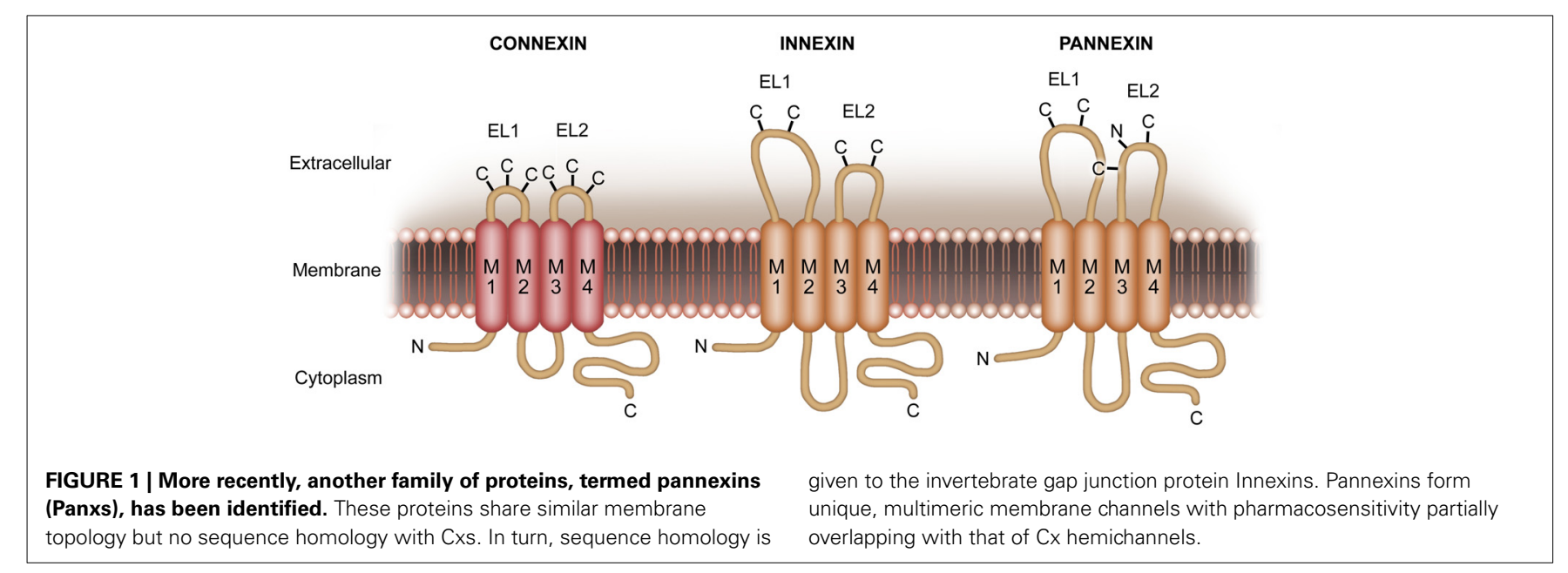

Table 1 | Summary of cell type specific expression of Cxs and Pxs as described until this point of time.

\begin{tabular}{|c|c|c|c|}
\hline Cell type & Connexin isoforms & Pannexin isoforms & Discussed by, a.o. \\
\hline Neurons & $26,30.2, \mathbf{3 6}, 45,57$ & 1,2 & $\begin{array}{l}\text { Condorelli et al., } 2000 \\
\text { Rouach et al., } 2002 \\
\text { Bruzzone et al., } 2003 \\
\text { Nagy et al., } 2004\end{array}$ \\
\hline Astrocytes & $26,30, \mathbf{4 3}, 40,45,46$ & 1 & $\begin{array}{l}\text { Nagy et al., } 2004 \\
\text { Giaume et al., } 2013\end{array}$ \\
\hline Oligodendrocytes/Myelin & $29,32,47$ & Not described & $\begin{array}{l}\text { Nagy et al., } 2004 \\
\text { Altevogt et al., } 2002 \\
\text { Li et al., } 2014\end{array}$ \\
\hline Microglia & $36, \mathbf{4 3}, 45$ & Not described & Mika and Prochnow, 2 \\
\hline
\end{tabular}

Bold typed isoforms are currently known to contribute to the course and development of traumatic brain injury (a.o., and others).

part in the regulation of neuronal death (Park et al., 2011). After the second postnatal week, coupling and expression of Cx36 physiologically decrease (Arumugam et al., 2005).

Due to spinal cord and TBI, gap junctional coupling and Cx36 expression by neurons increase in a pathophysiologic way (Chang et al., 2000; Frantseva et al., 2002a). A similar injurydependent upregulation of neuronal coupling occurs during ischemia (Oguro et al., 2001; De Pina-Benabou et al., 2005) and epilepsy (Gajda et al., 2003). Furthermore, the isoforms Cx26 and Cx32 can be expressed by neurons of the CNS (Bruzzone and Ressot, 1997; Dermietzel and Hofstadter, 1998; Teubner et al., 2001). Belousov and colleagues characterized the mechanisms that are responsible for the injury-mediated increase in neuronal gap junction coupling. Furthermore, they were able to describe a group II metabotropic glutamate receptor (mGluR) regulation dependent process in injury-induced neuronal death (Wang et al., 2012). It was shown that activation of group II mGluRs increases background levels of neuronal gap junction coupling and Cx36 expression. Inactivation of group II mGluRs prevents ischemic increase in coupling of Cx36 via cAMP/PKA-dependent signaling pathways (negatively coupled to the group II mGluRs) (Conn et al., 2005). Interestingly, other neurotransmitter receptors, including N-methyl-D-aspartate receptors (NMDAR), AMPA receptors, group I mGluRs, group III mGluRs, GABA $A$ receptors, and $\mathrm{GABA}_{\mathrm{B}}$ receptors did not directly contribute to these regulatory mechanisms (Wang et al., 2012). Similar results were obtained using three other in vitro injury models: hypo-osmotic shock, as a model of cytotoxic and osmotic edemas occurring during stroke and TBI (Unterberg et al., 2004); hydrostatic pressure injury, representing mechanical aspects of TBI (Morrison et al., 1998a,b) and administration of 4-aminopyridine, as a model of epileptic seizures (Wong and Yamada, 2001).

These observations led to the conclusion that group II mGluRs controls the injury-mediated increase in neuronal gap junction coupling. By regulation of neuronal gap junctions, they also control both death and survival mechanisms in injured neurons.

The critical factors for secondary neuronal cell death can be restricted to an excessive glutamate release from cells of the injured tissue, in turn causing local glutamate-dependent excitotoxicity. The excitotoxic mechanisms of glutamate include hyperactivation of NMDA receptors and increased $\mathrm{Ca}^{2+}$ ion influx. Furthermore, an overactivation of $\mathrm{Ca}^{2+}$-dependent signaling pathways is discussed to cause death of neurons (Choi, 1988; Arundine and Tymianski, 2004; Hazell, 2007). 
Based on the results of Belousov et al. (Belousov et al., 2012; Belousov and Fontes, 2013), a novel model for the mechanisms of glutamate-dependent excitotoxicity was proposed. This model implicates that overactivation of NMDAR is not only the main reason for glutamate-dependent neuronal death during neuronal injury. The process might be supported by the expression of neuronal gap junctions.

\section{ASTROGLIAL CONNEXINS}

TBI is mostly associated with excessive excitatory neurotransmitter release and subsequent cellular depolarization. This process, in turn, impacts on the degree of neuronal injury and glial reaction. The abrupt increase of extracellular glutamate subsequently drives an influx of $\mathrm{Ca}^{2+}$ ions, resulting into $\mathrm{Ca}^{2+}$-dependent excitotoxicity (Conti et al., 1998; Osteen et al., 2001). Another face of TBI is the rapid loss of astrocytes and the substitutive induction of reactive astrocytes, as it could be demonstrated in the Hippocampus in animal models (Dietrich et al., 1994; Zhao et al., 2003). Studies of Nakase et al. (2003) gave rise for a predominant role of astroglial $\mathrm{Cx} 43$-gap junctions in the reduction of neuronal apoptosis under ischemic conditions, influencing infarct volumes and caspase- 3 levels. Furthermore, the physiologically relevant portion of glial fibrillary acidic protein (GFAP) - positive astrocytes could be primarily attributed to $\mathrm{Cx} 43$ expressing mice. Knockout models showed that a lack of $\mathrm{Cx} 43$ expression is aligned with strongly reduced levels in GFAP expression, leading to pathophysiological conditions of the neuro-glial syncythium (Nakase et al., 2003). Cx43 and Cx30 are primarily localized on astrocytes, whereas $\mathrm{Cx} 29,32$, and 47 are predominantly expressed on oligodendrocytes (Bruzzone and Ressot, 1997; Dermietzel and Hofstadter, 1998; Teubner et al., 2001).

Regarding functionality, the intracellular condition and state of phosphorylation of the Connexin proteins influence the intercellular permeability characteristics of gap junctions. In this context it was demonstrated that extracellular signal-regulated kinase (ERK) mediated phosphorylation of $\mathrm{Cx} 43$ strongly reduced the intercellular permeability of gap junctions (Brandes et al., 2002; Cottrell et al., 2003). These findings correlate well with later findings of Ohsumi et al. (2010) who investigated the expression of phosphorylated $\mathrm{Cx} 43$ in the rat hippocampus following experimental TBI in vivo. The authors showed by the use of immunochemistry that high levels of phosphorylated $\mathrm{Cx} 43$ were present in astrocytes of the hippocampal CA3 of the TBI exposed hemisphere for up to $6 \mathrm{~h}$. Subsequent upregulation of phosphorylated ERK coincided with the $\mathrm{Cx} 43$ expression and gave rise to a participation of astrocytic gap junctions in the hippocampal pathophysiology following TBI (Ohsumi et al., 2010).

It is critically discussed whether propagation of stress factors (including apoptotic factors) via astroglial gap junctions might impact on the process of secondary brain damage after TBI which is mostly correlated to ischemic injury (Hossmann, 1994; Lin et al., 1998; Frantseva et al., 2002a). This hypothesis became strengthened by findings of Frantseva and colleagues who demonstrated that neuronal cell death after hypoxic-hypoglycemic insults is reduced in CNS slices treated with antisense oligonucleotides for $\mathrm{Cx} 43$. Propagation of secondary cell injury to neighbored cells via astrocytic gap junctions was demonstrated in
1998. It was shown that astrocytic $\mathrm{Cx} 43$ based gap junctions mediate transcellular signals, enhancing calcium overload, oxidative stress, and metabolic inhibition (Lin et al., 1998). On the other hand Nakase et al. (2003) suggested that astrocytic gap junctions facilitate the establishment of a reactive astrocytic network and remove cytotoxic factors (Nakase et al., 2003). This would also underline the indication that mechanisms of spreading depression after TBI or ischemic insults trigger neuronal as well as glial depolarization, and thereafter tend to induce neuronal damage (Katayama et al., 1990; Nedergaard and Hansen, 1993).

Especially in the context of cerebral ischemia, selective blockade of Cx43 hemichannels by mimetic peptide application significantly improved the neuronal outcome in fetal sheep. This finding was in particular due to a hemichannel blockade following, but not during global cerebral ischemia in the near-term fetal condition (Davidson et al., 2013). Recently, Orellana et al. (2013) discussed the role of $\mathrm{Cx}$ hemichannels as diffusional pathways for ions and small molecules between the intra- and extracellular compartments and suggest that channel opening may gate the release of neurotoxic substances (e.g., glutamate, external $\mathrm{Ca}^{2+}$-overload) (Orellana et al., 2011). Here, putative operators, facilitating channel activity can be cytokines such as Tumor Necrosis Factor-alpha or Interleukin1- $\beta$ (Froger et al., 2010). In other cases, hemichannels may confer neuroprotection against an ischemic episode by the phenomenon of ischemic preconditioning (Bennett et al., 2012).

Nevertheless, it can be summarized to this point that the cell type specific expression of neuronal and astroglial Cxs seems to be dynamic and influenced by the environmental signals that are induced by TBI. The role of neuronal and astroglial Cxs in neuronal cell death as well as their role in neuroprotection increase in therapeutic importance.

\section{PANNEXINS AND TBI}

Addressing Pannexin functions, especially in the context of neurotrauma, we enter a young field in CNS research. In 2003, three Innexin homologs were cloned from rats and mice, the isoforms Px1, Px2, and Px3. Since nothing is known about the role of the latter two isoforms in TBI, this paragraph focusses on the sparse facts about Pxl in neuroinflammation and induced neurotrauma-like conditions. Pannexin 1 is ubiquitously expressed in the mammalian CNS (Bruzzone et al., 2003; Ray et al., 2005), covering cells of the retina, olfactory bulb, neocortex, hippocampus, cerebellum, and spinal cord. Pannexin1 is described to act as an ATP release channel with unselective high conductance properties (Prochnow et al., 2009; Kurtenbach et al., 2013). Opening of this large pore channel can be initiated by depolarizing voltage sensing or hyposmolar/mechanical activation (Iglesias and Spray, 2012; Krizaj et al., 2013). Regarding traumatic injury of the CNS, the mechanical stress related activation process of Panxl gains special interest. With focus on inflammatory processes, neuronal Px1 was shown to closely operate together with stimulus-induced opening of astroglial Cx43 hemichannels with. According to this, pharmacologic inhibition of NMDA or P2X receptors only partially reduced the activation of neuronal Panx1 hemichannels and neuronal mortality 
(Orellana et al., 2011). Simultaneous inhibition of both receptors completely prevented the neurotoxic response. The authors suggested that responses to ATP and glutamate converge in activation of neuronal Panxl hemichannels. It was proposed that blocking hemichannels expressed by astrocytes and/or neurons in the inflamed nervous system could represent a novel and alternative strategy to reduce neuronal loss in various pathological states including ischemia which often concomitantly occurs as a consequence of TBI.

\section{EXPERIMENTAL MODELS ELUCIDATING THE FUNCTION OF CONNEXINS AND PANNEXINS IN TBI}

Sudden cumulation of extracellular glutamate after TBI results into an increase of intracellular $\mathrm{Ca}^{2+}$ ion which, in turn, leads to $\mathrm{Ca}^{2+}$-dependent excitotxicity (Conti et al., 1998; Osteen et al., 2001). Animal models reveal that vulnerability of CNS structures does not follow a homogenous propagation pattern, in contrast, selective vulnerability is observed for certain regions such as CA3 pyramidal neurons, dentate hilar neurons, and cortical neurons (Lowenstein et al., 1992; Cortez et al., 1995; Nawashiro et al., 1995). These results were primarily obtained from fluid percussion induced neurotraumatization (McIntosh et al., 1989) in rats. In this experimental setting, focal brain injury was performed by application of fluid pulse (2.6-2.8 atm; $12 \mathrm{~ms}$ duration) on the intact dura following osteotomy in the anaesthetized animal. By this approach, Ohsumi et al. investigated the temporal and spatial expression profiles of $\mathrm{Cx} 43$ in the hippocampal CA3 region of adult rats (Ohsumi et al., 2010). Using Western blot analysis and immunohistochemistry the authors were able to show that phosphorylated $\mathrm{Cx} 43$ is strongly increased in astrocytes of the perilesion sites $1 \mathrm{~h}$ after TBI and lasting for the next $24 \mathrm{~h}$. In contrast, no distinct pattern of phosphorylated $\mathrm{Cx} 43$ expression was found in the neighbored hippocampal CA1 region. Immunoreactivity of the total amount of $\mathrm{Cx} 43$ was unchanged. Based on these facts, the authors suggested that time-dependent phosphorylation of $\mathrm{Cx} 43$ contributes to hippocampal dysfunction via astrocytic gap junction communication and serves as a prodromal. Total Cx43 immunoreactivity was localized in astrocytes in the direct periphery of the contusion focus at $72 \mathrm{~h}$ post TBI. This probably directly reflects the anatomical correlate for potentiation of intercellular signaling via gap junction transduction. This process might be beneficial to restoring of neuronal damage during the late phase of injury.

In analogy to an increased occurrence in war zones and due to terrorist incidents (Risdall and Menon, 2011), another set of approaches covers blast-induced traumatic brain injuries in animal models (Wolf et al., 2009). Also in this type of experimental setting, utilizing controlled $60 \mathrm{mg}$ TNT blasts in a described vicinity of rabbit skulls, an increase in $\mathrm{Cx} 43$ and caspase- 3 expression could by detected in the penumbral regions. Caspase- 3 is one of the downstream pro-apoptotic factors, discussed as a candidate to be transmitted via gap junction communication during TBI (Wennersten et al., 2003; Yong-Ming et al., 2012).

Providing a target for putative treatment the penumbra region of TBI delineates, as a locus for delayed responses, the primary injury core from the intact brain region (Paciaroni et al.,
2009). The region itself reveals a centralized pattern of astroglial Cx43 expression which is described to be related to ischemic processes (Hossain et al., 1994). Later on it was demonstrated that $\mathrm{Cx} 29$ and $\mathrm{Cx} 32$ are expressed in a subset of microglia and astrocytes in the sharp border of the penumbra (Moon et al., 2010). The data were obtained from a cryogenic TBI model in mice where a liquid nitrogen filled iron rod is directly placed on the cranium of the anaesthetized animal (Tatsumi et al., 2005). The authors suggested a Connexin-mediated influence on cellular degeneration/regeneration information between the core and the periphery of the injury. This finding was also underlined by knockout animal studies. As an example, knockout of the Cx32 gene enhanced neuronal vulnerability (Oguro et al., 2001; Moon et al., 2010), whereas knockout of the Cx43 gene resulted in the previously described decreased neuronal vulnerability after TBI (Frantseva et al., 2002a).

Regarding the investigation of Pannexin channel function due to neurotrauma the only reliable model are specified weight drop experiments by Wang et al., on the spinal cord in mice (Wang et al., 2004). In the weight drop approach, a standardized neurotrauma is induced by dropping a small weight into a predefined area of the spinal cord. By help of this attempt, Wang and colleagues showed that ATP was released in the penumbral region leading to a massive recruitment of microglial, macrophage, and monocyte derived cells. The process was followed by secondary expansion of the lesion (Wang et al., 2004). The authors were also able to identify the contribution of $\mathrm{P} 2 \mathrm{X}$ receptor activation and neuronal excitation in direct subsequence to the lesion process. Evidence was provided by targeting direct pharmacological inhibition of ATP-P2X7 receptor interaction and application of $\mathrm{P} 2 \mathrm{X} 7$ receptor antagonists. In combination with previous findings of Nedergaard and colleagues (Wang et al., 2004; Peng et al., 2009) these results gave first rise for an involvement of Px1 interaction with P2X7 receptors in the course of neurotrauma.

Another sophisticated approach was given by Davalos et al. (2005). The authors investigated the fast microglial response according to local two-photon laser mediated ablation of the superficial layer of the motor cortex and mechanical tissue manipulation via a glass microelectrode. Wang et al., as well as Davalos et al., reported and mimicked the effects of locally released ATP. Davalos and colleagues showed that local increases in ATP levels, as it can be supported by Pxl operated release from astrocytes and neurons, influence the chemotactic guidance of microglial processes toward the borders of the penumbral region in mice in vivo. The process is carried out without movement of the cells' somata and can be mimicked by local application of ATP and subsequent activation of P2Y receptors. Additionally the baseline motility of microglial processes was slowed down under application of ATP-degrading apyrase and Connexin channel inhibitors, indicating that the interplay of both, Connexins and Pannexins seems to be needful in the cellular response toward injury. Nevertheless, the different types of experiments underline that severity and type of traumatization can impact on Px1- and Cx-dependent systems in relevant modulatory ways with influence on the future development of the injury site. 


\section{FROM EXPERIMENTS TO BEDSIDE? A YOUNG CHAPTER}

Based on the actual results from in vitro and in vivo related experiments, Connexins appear to be the most important player in the intercellular neuroglial pathosphysiology of the CNS during TBI. At the moment, an effective therapeutic agent for TBI remains elusive (Wang et al., 2006; Beauchamp et al., 2008; Elliott et al., 2011).

The astroglial expression site of Cx43 (Garre et al., 2010) might play an important role in future clinical treatment. Since description is pending that stress factors, including apoptotic factors, are passed through gap junctions, the hypothesis was established that a partial decrease in neuronal or glial gap junction mediated communication might be sufficient to reduce secondary tissue damage. The hypothesis became strengthened by studies of Frantseva et al. who proved that cell death is reduced in native CNS slices following treatment with antisense oligonucleotides for Cx43 after hypoxic-glycemic insult (Frantseva et al., 2002b). Pharmacological inhibition of $\mathrm{Cx} 43$ activity was performed in a multitude of TBI studies. Here, gap junction blockers such as insulin (Homma et al., 1998) octanol (Rawanduzy et al., 1997) and carbenoxolone (De Pina-Benabou et al., 2005) were shown to exhibit neuroprotective effects in diverse models of cerebral injury. Especially the latter one is also serving as a non-specific Px1-inhibitor.

Stem cell therapy promises another treatment option of TBI. In order to reestablish neuronal networks in the perilesion regions, the functional integration of grafted neuronal stem cells might provide a perspective. In this context the property of $\mathrm{Cx} 43$ based cellular coupling should serve as a means to link endogenous and exogenous network components together. Aside from the expression on astrocytes, $\mathrm{Cx} 43$ is most closely associated with immature neuronal stem cells (Jaderstad et al., 2010; Yu et al., 2013). One proposed way in which grafted neuronal stem cells integrate into host tissues is gap junction coupling. The exogenous stem cells are described to protect the host neurons from cell death as well as reducing signs of secondary injury such as reactive gliosis. Experiments in vivo and in vitro revealed that these beneficial effects were lacking, when gap junction communication was suppressed in the host (Jaderstad et al., 2010). Yu et al. (2013) underlined these findings by showing that neuronal stem cell transplantation significantly enhanced the $\mathrm{Cx} 43$ protein expression in a rat model of controlled cortical impact TBI (Ma et al., 2011). Connexin43 expression after transplantation was increased in the core and the border of injury. These expression levels were maintained for up to 4 weeks post transplantation, giving rise that gap junctions based on $\mathrm{Cx} 43$ might participate in the iterative developmental process of graft integration into the host CNS tissue following TBI. Although it is becoming recognized that grafted neuronal stem cells interact with endogenous neurons of the peritransplant region, the underlying mechanisms remain to be matter to intensified research.

Since approximately $85-89 \%$ of TBI patients show non-open trauma injuries e.g., caused by traffic accidents (Masson et al., 2001; Wu et al., 2008), local pharmacological treatment or stem cell delivery to the host tissue still provides a problem.

An actual pharmacological intersection between basic research and applied treatment of TBI is given by the patient administration of cannabinoid receptor agonists including $\Delta^{9}$ tetrahydrocannabinol or nabilone. These substances are clinically used in the suppression of multiple sclerosis and spinal cord injury symptoms, as well as for the prevention of neurotoxicity (Pertwee, 2006). Interestingly, cannabinoid receptor agonists influence $\mathrm{Cx} 43$ regulation in culture models under proinflammatory conditions in a preventive manner mediated by CB1 receptor activation (Froger et al., 2009). On the one hand Froger et al. demonstrated that cannabinoid agonists prevent the inhibition of gap junction coupling of astrocytes induced by conditioned medium harvested from LPS-activated microglia. On the other hand the authors showed via dye coupling and ethidium uptake experiments in astrocyte cultures the dual regulation of Cx43 functions induced by IL- $1 \beta$ and TNF- $\alpha$.

These results of cannabinoid-Cx interaction provide evidence for an indirect mechanism to impact on Cx43 activity in a traumatic/pro-inflammatory condition as it might act already in clinical routine.

\section{ACKNOWLEDGMENTS}

I especially thank Helga Schulze for excellent illustrating, as well as Cindy Richter and Thomas Mika for internal correspondence.

\section{REFERENCES}

Altevogt, B. M., Kleopa, K. A., Postma, F. R., Scherer, S. S., and Paul, D. L. (2002). Connexin 29 is uniquely distributed within myelinating glial cells of the central and peripheral nervous systems. J. Neurosci. 22, 6458-6470.

Arumugam, H., Liu, X., Colombo, P. J., Corriveau, R. A., and Belousov, A. B. (2005). NMDA receptors regulate developmental gap junction uncoupling via CREB signaling. Nat. Neurosci. 8, 1720-1726. doi: 10.1038/nn1588

Arundine, M., and Tymianski, M. (2004). Molecular mechanisms of glutamatedependent neurodegeneration in ischemia and traumatic brain injury. Cell Mol. Life Sci. 61, 657-668. doi: 10.1007/s00018-003-3319-x

Avila, M. A., Sell, S. L., Hawkins, B. E., Hellmich, H. L., Boone, D. R., Crookshanks, J. M., et al. (2011). Cerebrovascular connexin expression: effects of traumatic brain injury. J. Neurotrauma 28, 1803-1811. doi: 10.1089/neu.2011.1900

Bao, L., Locovei, S., and Dahl, G. (2004). Pannexin membrane channels are mechanosensitive conduits for ATP. FEBS Lett. 572, 65-68. doi: 10.1016/j.febslet.2004.07.009

Baranova, A., Ivanov, D., Petrash, N., Pestova, A., Skoblov, M., Kelmanson, I., et al. (2004). The mammalian pannexin family is homologous to the invertebrate innexin gap junction proteins. Genomics 83, 706-716. doi: 10.1016/j.ygeno.2003.09.025

Bargiotas, P., Krenz, A., Hormuzdi, S. G., Ridder, D. A., Herb, A., Barakat, W., et al. (2011). Pannexins in ischemia-induced neurodegeneration. Proc. Natl. Acad. Sci. U.S.A. 108, 20772-20777. doi: 10.1073/pnas.1018262108

Beauchamp, K., Mutlak, H., Smith, W. R., Shohami, E., and Stahel, P. F. (2008) Pharmacology of traumatic brain injury: where is the "golden bullet?" Mol. Med. 14, 731-740. doi: 10.2119/2008-00050.Beauchamp

Belluardo, N., Mudo, G., Trovato-Salinaro, A., Le Gurun, S., Charollais, A., SerreBeinier, V., et al. (2000). Expression of Connexin36 in the adult and developing rat brain. Brain Res. 865, 121-138. doi: 10.1016/S0006-8993(00)02300-3

Belousov, A. B., and Fontes, J. D. (2013). Neuronal gap junctions: making and breaking connections during development and injury. Trends Neurosci. 36, 227-236. doi: 10.1016/j.tins.2012.11.001

Belousov, A. B., Wang, Y., Song, J. H., Denisova, J. V., Berman, N. E., and Fontes, J. D. (2012). Neuronal gap junctions play a role in the secondary neuronal death following controlled cortical impact. Neurosci. Lett. 524, 16-19. doi: 10.1016/j.neulet.2012.06.065

Bennett, M. V., Garre, J. M., Orellana, J. A., Bukauskas, F. F., Nedergaard, M., and Saez, J. C. (2012). Connexin and pannexin hemichannels in inflammatory responses of glia and neurons. Brain Res. 1487, 3-15. doi: 10.1016/j.brainres.2012.08.042

Berthoud, V. M., and Beyer, E. C. (2009). Oxidative stress, lens gap junctions, and cataracts. Antioxid. Redox Signal. 11, 339-353. doi: 10.1089/ars.2008.2119 
Brandes, R. P., Popp, R., Ott, G., Bredenkotter, D., Wallner, C., Busse, R., et al. (2002). The extracellular regulated kinases (ERK) $1 / 2$ mediate cannabinoid-induced inhibition of gap junctional communication in endothelial cells. Br. J. Pharmacol. 136, 709-716. doi: 10.1038/sj.bjp. 0704776

Bruzzone, R., Hormuzdi, S. G., Barbe, M. T., Herb, A., and Monyer, H. (2003). Pannexins, a family of gap junction proteins expressed in brain. Proc. Natl. Acad. Sci. U.S.A. 100, 13644-13649. doi: 10.1073/pnas.2233464100

Bruzzone, R., and Ressot, C. (1997). Connexins, gap junctions and cell-cell signalling in the nervous system. Eur. J. Neurosci. 9, 1-6. doi: 10.1111/j.14609568.1997.tb01346.x

Chang, Q., Pereda, A., Pinter, M. J., and Balice-Gordon, R. J. (2000). Nerve injury induces gap junctional coupling among axotomized adult motor neurons. J. Neurosci. 20, 674-684.

Choi, D. W. (1988). Glutamate neurotoxicity and diseases of the nervous system. Neuron 1, 623-634. doi: 10.1016/0896-6273(88)90162-6

Condorelli, D. F., Belluardo, N., Trovato-Salinaro, A., and Mudo, G. (2000). Expression of Cx36 in mammalian neurons. Brain Res. Brain Res. Rev. 32, 72-85. doi: 10.1016/S0165-0173(99)00068-5

Conn, P. J., Battaglia, G., Marino, M. J., and Nicoletti, F. (2005). Metabotropic glutamate receptors in the basal ganglia motor circuit. Nat. Rev. Neurosci. 6, 787-798. doi: 10.1038/nrn1763

Conti, F., Debiasi, S., Minelli, A., Rothstein, J. D., and Melone, M. (1998). EAAC1, a high-affinity glutamate tranporter, is localized to astrocytes and gabaergic neurons besides pyramidal cells in the rat cerebral cortex. Cereb. Cortex 8, 108-116. doi: 10.1093/cercor/8.2.108

Cortez, D., Kadlec, L., and Pendergast, A. M. (1995). Structural and signaling requirements for BCR-ABL-mediated transformation and inhibition of apoptosis. Mol. Cell. Biol 15, 5531-5541.

Cottrell, G. T., Lin, R., Warn-Cramer, B. J., Lau, A. F., and Burt, J. M. (2003). Mechanism of v-Src- and mitogen-activated protein kinase-induced reduction of gap junction communication. Am. J. Physiol. Cell Physiol. 284, C511-C520. doi: 10.1152/ajpcell.00214.2002

Davalos, D., Grutzendler, J., Yang, G., Kim, J. V., Zuo, Y., Jung, S., et al. (2005). ATP mediates rapid microglial response to local brain injury in vivo. Nat. Neurosci. 8, 752-758. doi: $10.1038 / \mathrm{nn} 1472$

Davidson, J. O., Green, C. R., Nicholson, L. F., Bennet, L., and Gunn, A. J. (2013). Connexin hemichannel blockade is neuroprotective after, but not during, global cerebral ischemia in near-term fetal sheep. Exp. Neurol. 248, 301-308. doi: 10.1016/j.expneurol.2013.06.026

De Pina-Benabou, M. H., Szostak, V., Kyrozis, A., Rempe, D., Uziel, D., UrbanMaldonado, M., et al. (2005). Blockade of gap junctions in vivo provides neuroprotection after perinatal global ischemia. Stroke 36, 2232-2237. doi: 10.1161/01.STR.0000182239.75969.d8

Dermietzel, R., and Hofstadter, F. (1998). Gap junctions in health and disease. Virchows Arch. 432, 177-186. doi: 10.1007/s004280050153

Dietrich, W. D., Alonso, O., Busto, R., and Ginsberg, M. D. (1994). Widespread metabolic depression and reduced somatosensory circuit activation following traumatic brain injury in rats. J. Neurotrauma 11, 629-640. doi: 10.1089/neu.1994.11.629

Elliott, M. B., Tuma, R. F., Amenta, P. S., Barbe, M. F., and Jallo, J. I. (2011). Acute effects of a selective cannabinoid-2 receptor agonist on neuroinflammation in a model of traumatic brain injury. J. Neurotrauma 28, 973-981. doi: $10.1089 /$ neu.2010.1672

Eugenin, E. A., Basilio, D., Saez, J. C., Orellana, J. A., Raine, C. S., Bukauskas, F., et al. (2012). The role of gap junction channels during physiologic and pathologic conditions of the human central nervous system. J. Neuroimmune Pharmacol. 7, 499-518. doi: 10.1007/s11481-012-9352-5

Frantseva, M. V., Kokarovtseva, L., Naus, C. G., Carlen, P. L., Macfabe, D., and Perez Velazquez, J. L. (2002a). Specific gap junctions enhance the neuronal vulnerability to brain traumatic injury. J. Neurosci. 22, 644-653.

Frantseva, M. V., Kokarovtseva, L., and Perez Velazquez, J. L. (2002b). Ischemia-induced brain damage depends on specific gap-junctional coupling. J. Cereb. Blood Flow Metab. 22, 453-462. doi: 10.1097/00004647-20020400000009

Froger, N., Orellana, J. A., Calvo, C. F., Amigou, E., Kozoriz, M. G., Naus, C. C., et al. (2010). Inhibition of cytokine-induced connexin 43 hemichannel activity in astrocytes is neuroprotective. Mol. Cell. Neurosci. 45, 37-46. doi: 10.1016/j.mcn.2010.05.007
Froger, N., Orellana, J. A., Cohen-Salmon, M., Ezan, P., Amigou, E., Saez, J. C., et al. (2009). Cannabinoids prevent the opposite regulation of astroglial Connexin 43 hemichannels and gap junction channels induced by pro-inflammatory treatments. J. Neurochem. 111, 1383-1397. doi: 10.1111/j.1471-4159.2009.06407.x

Gajda, Z., Gyengesi, E., Hermesz, E., Ali, K. S., and Szente, M. (2003). Involvement of gap junctions in the manifestation and control of the duration of seizures in rats in vivo. Epilepsia 44, 1596-1600. doi: 10.1111/j.0013-9580.2003.25803.x

Garre, J. M., Retamal, M. A., Cassina, P., Barbeito, L., Bukauskas, F. F., Saez, J. C., et al. (2010). FGF-1 induces ATP release from spinal astrocytes in culture and opens pannexin and Connexin hemichannels. Proc. Natl. Acad. Sci. U.S.A. 107, 22659-22664. doi: 10.1073/pnas.1013793107

Giaume, C., Leybaert, L., Naus, C. C., and Saez, J. C. (2013). Connexin and pannexin hemichannels in brain glial cells: properties, pharmacology, and roles. Front. Pharmacol. 4:88. doi: 10.3389/fphar.2013.00088

Giaume, C., and Theis, M. (2010). Pharmacological and genetic approaches to study Connexin-mediated channels in glial cells of the central nervous system. Brain Res. Rev. 63, 160-176. doi: 10.1016/j.brainresrev.2009.11.005

Hamzei-Sichani, F., Kamasawa, N., Janssen, W. G., Yasumura, T., Davidson, K. G., Hof, P. R., et al. (2007). Gap junctions on hippocampal mossy fiber axons demonstrated by thin-section electron microscopy and freeze fracture replica immunogold labeling. Proc. Natl. Acad. Sci. U.S.A. 104, 12548-12553. doi: 10.1073/pnas.0705281104

Hazell, A. S. (2007). Excitotoxic mechanisms in stroke: an update of concepts and treatment strategies. Neurochem. Int. 50, 941-953. doi: 10.1016/j.neuint.2007.04.026

Homma, N., Alvarado, J. L., Coombs, W., Stergiopoulos, K., Taffet, S. M., Lau, A. F., et al. (1998). A particle-receptor model for the insulin-induced closure of Connexin 43 channels. Circ. Res. 83, 27-32. doi: 10.1161/01.RES.83.1.27

Hossain, M. Z., Peeling, J., Sutherland, G. R., Hertzberg, E. L., and Nagy, J. I. (1994). Ischemia-induced cellular redistribution of the astrocytic gap junctional protein Connexin 43 in rat brain. Brain Res. 652, 311-322. doi: 10.1016/00068993(94)90242-9

Hossmann, K. A. (1994). Glutamate-mediated injury in focal cerebral ischemia: the excitotoxin hypothesis revised. Brain Pathol. 4, 23-36. doi: 10.1111/j.17503639.1994.tb00808.x

Iglesias, R. M., and Spray, D. C. (2012). Pannexin1-mediated ATP release provides signal transmission between Neuro2A cells. Neurochem. Res. 37, 1355-1363. doi: 10.1007/s11064-012-0720-6

Jaderstad, J., Jaderstad, L. M., Li, J., Chintawar, S., Salto, C., Pandolfo, M., et al. (2010). Communication via gap junctions underlies early functional and beneficial interactions between grafted neural stem cells and the host. Proc. Natl. Acad. Sci. U.S.A. 107, 5184-5189. doi: 10.1073/pnas.0915134107

Katayama, Y., Becker, D. P., Tamura, T., and Tsubokawa, T. (1990). Cellular swelling during cerebral ischaemia demonstrated by microdialysis in vivo: preliminary data indicating the role of excitatory amino acids. Acta Neurochir. Suppl. (Wien) 51, 183-185. doi: 10.1007/978-3-7091-9115-6_62

Krizaj, D., Ryskamp, D. A., Tian, N., Tezel, G., Mitchell, C. H., Slepak, V. Z., et al. (2013). From mechanosensitivity to inflammatory responses: new players in the pathology of glaucoma. Curr. Eye Res. 39, 105-119. doi: 10.3109/02713683.2013. 836541

Kurtenbach, S., Prochnow, N., Kurtenbach, S., Klooster, J., Zoidl, C., Dermietzel, R., et al. (2013). Pannexinl channel proteins in the zebrafish retina have shared and unique properties. PLoS ONE 8:e77722. doi: 10.1371/journal.pone.0077722

Li, T., Giaume, C., and Xiao, L. (2014). Connexins-mediated glia networking impacts myelination and remyelination in the central nervous system. Mol. Neurobiol. doi: 10.1007/s12035-013-8625-1. [Epub ahaed of print].

Lin, J. H., Weigel, H., Cotrina, M. L., Liu, S., Bueno, E., Hansen, A. J., et al. (1998). Gap-junction-mediated propagation and amplification of cell injury. Nat. Neurosci. 1, 494-500. doi: 10.1038/2210

Locovei, S., Bao, L., and Dahl, G. (2006a). Pannexin 1 in erythrocytes: function without a gap. Proc. Natl. Acad. Sci. U.S.A. 103, 7655-7659. doi: 10.1073/pnas.0601037103

Locovei, S., Wang, J., and Dahl, G. (2006b). Activation of pannexin 1 channels by ATP through P2Y receptors and by cytoplasmic calcium. FEBS Lett. 580, 239-244. doi: 10.1016/j.febslet.2005.12.004

Lowenstein, D. H., Thomas, M. J., Smith, D. H., and McIntosh, T. K. (1992). Selective vulnerability of dentate hilar neurons following traumatic brain injury: a potential mechanistic link between head trauma and disorders of the hippocampus. J. Neurosci. 12, 4846-4853. 
Lu, J., Roe, C., Aas, E., Lapane, K. L., Niemeier, J., Arango-Lasprilla, J. C., et al. (2013). Traumatic brain injury: methodological approaches to estimate healthand economic outcomes. J. Neurotrauma 30, 1925-1933. doi: 10.1089/neu.2013. 2891

Ma, H., Yu, B., Kong, L., Zhang, Y., and Shi, Y. (2011). Transplantation of neural stem cells enhances expression of synaptic protein and promotes functional recovery in a rat model of traumatic brain injury. Mol. Med. Rep. 4, 849-856. doi: 10.3892/mmr.2011.510

Macvicar, B. A., and Thompson, R. J. (2010). Non-junction functions of pannexin1 channels. Trends Neurosci. 33, 93-102. doi: 10.1016/j.tins.2009.11.007

Masson, F., Thicoipe, M., Aye, P., Mokni, T., Senjean, P., Schmitt, V., et al. (2001). Epidemiology of severe brain injuries: a prospective population-based study. J. Trauma 51, 481-489. doi: 10.1097/00005373-200109000-00010

McIntosh, T. K., Vink, R., Noble, L., Yamakami, I., Fernyak, S., Soares, H., et al. (1989). Traumatic brain injury in the rat: characterization of a lateral fluid-percussion model. Neuroscience 28, 233-244. doi: 10.1016/03064522(89)90247-9

Mika, T., and Prochnow, N. (2012). Functions of Connexins and large pore channels on microglial cells: the gates to environment. Brain Res. 1487, 16-24. doi: 10.1016/j.brainres.2012.07.020

Moon, Y., Choi, S. Y., Kim, K., Kim, H., and Sun, W. (2010). Expression of Connexin29 and 32 in the penumbra region after traumatic brain injury of mice. Neuroreport 21, 1135-1139. doi: 10.1097/WNR.0b013e32834051c7

Morrison, B. 3rd., Meaney, D. F., and McIntosh, T. K. (1998a). Mechanical characterization of an in vitro device designed to quantitatively injure living brain tissue. Ann. Biomed. Eng. 26, 381-390. doi: 10.1114/1.61

Morrison, B. 3rd., Saatman, K. E., Meaney, D. F., and McIntosh, T. K. (1998b). In vitro central nervous system models of mechanically induced trauma: a review. J. Neurotrauma 15, 911-928. doi: 10.1089/neu.1998.15.911

Nagy, J. I., Dudek, F. E., and Rash, J. E. (2004). Update on connexins and gap junctions in neurons and glia in the mammalian nervous system. Brain Res. Brain Res. Rev. 47, 191-215. doi: 10.1016/j.brainresrev.2004.05.005

Nakase, T., Fushiki, S., and Naus, C. C. (2003). Astrocytic gap junctions composed of Connexin 43 reduce apoptotic neuronal damage in cerebral ischemia. Stroke 34, 1987-1993. doi: 10.1161/01.STR.0000079814.72027.34

Nawashiro, H., Shima, K., and Chigasaki, H. (1995). Selective vulnerability of hippocampal CA3 neurons to hypoxia after mild concussion in the rat. Neurol. Res. $17,455-460$.

Nedergaard, M., and Hansen, A. J. (1993). Characterization of cortical depolarizations evoked in focal cerebral ischemia. J. Cereb. Blood Flow Metab. 13, 568-574. doi: $10.1038 /$ jcbfm.1993.74

Oguro, K., Jover, T., Tanaka, H., Lin, Y., Kojima, T., Oguro, N., et al. (2001). Global ischemia-induced increases in the gap junctional proteins Connexin 32 (Cx32) and $\mathrm{Cx} 36$ in hippocampus and enhanced vulnerability of $\mathrm{Cx} 32$ knock-out mice. J. Neurosci. 21, 7534-7542.

Ohsumi, A., Nawashiro, H., Otani, N., Ooigawa, H., Toyooka, T., and Shima, K. (2010). Temporal and spatial profile of phosphorylated Connexin 43 after traumatic brain injury in rats. J. Neurotrauma 27, 1255-1263. doi: 10.1089/neu.2009.1234

Orellana, J. A., Froger, N., Ezan, P., Jiang, J. X., Bennett, M. V., Naus, C. C., et al. (2011). ATP and glutamate released via astroglial connexin 43 hemichannels mediate neuronal death through activation of pannexin 1 hemichannels. J. Neurochem. 118, 826-840. doi: 10.1111/j.1471-4159.2011.07210.x

Orellana, J. A., Montero, T. D., and Von Bernhardi, R. (2013). Astrocytes inhibit nitric oxide-dependent $\mathrm{Ca}(2+)$ dynamics in activated microglia: involvement of ATP released via pannexin 1 channels. Glia 61, 2023-2037. doi: 10.1002/glia.22573

Osteen, C. L., Moore, A. H., Prins, M. L., and Hovda, D. A. (2001). Age-dependency of 45 calcium accumulation following lateral fluid percussion: acute and delayed patterns. J. Neurotrauma 18, 141-162. doi: 10.1089/08977150150502587

Paciaroni, M., Caso, V., and Agnelli, G. (2009). The concept of ischemic penumbra in acute stroke and therapeutic opportunities. Eur. Neurol. 61, 321-330. doi: $10.1159 / 000210544$

Panchin, Y., Kelmanson, I., Matz, M., Lukyanov, K., Usman, N., and Lukyanov, S. (2000). A ubiquitous family of putative gap junction molecules. Curr. Biol. 10, R473-R474. doi: 10.1016/S0960-9822(00) 00576-5

Panchin, Y. V. (2005). Evolution of gap junction proteins-the pannexin alternative. J. Exp. Biol. 208, 1415-1419. doi: 10.1242/jeb.01547
Park, W. M., Wang, Y., Park, S., Denisova, J. V., Fontes, J. D., and Belousov, A. B. (2011). Interplay of chemical neurotransmitters regulates developmental increase in electrical synapses. J. Neurosci. 31, 5909-5920. doi: 10.1523/JNEUROSCI.6787-10.2011

Pelegrin, P., and Surprenant, A. (2006). Pannexin-1 mediates large pore formation and interleukin-1beta release by the ATP-gated P2X7 receptor. EMBO J. 25, 5071-5082. doi: 10.1038/sj.emboj.7601378

Pelegrin, P., and Surprenant, A. (2007). Pannexin-1 couples to maitotoxin- and nigericin-induced interleukin-1beta release through a dye uptake-independent pathway. J. Biol. Chem. 282, 2386-2394. doi: 10.1074/jbc.M610351200

Peng, W., Cotrina, M. L., Han, X., Yu, H., Bekar, L., Blum, L., et al. (2009). Systemic administration of an antagonist of the ATP-sensitive receptor P2X7 improves recovery after spinal cord injury. Proc. Natl. Acad. Sci. U.S.A. 106, 12489-12493. doi: 10.1073/pnas.0902531106

Pertwee, R. G. (2006). The pharmacology of cannabinoid receptors and their ligands: an overview. Int. J. Obes. (Lond.) 1, S13-S18. doi: 10.1038/sj.ijo.0803272

Prochnow, N., Abdulazim, A., Kurtenbach, S., Wildforster, V., Dvoriantchikova, G., Hanske, J., et al. (2012). Pannexin1 stabilizes synaptic plasticity and is needed for learning. PLOS ONE 7:e51767. doi: 10.1371/journal.pone. 0051767

Prochnow, N., and Dermietzel, R. (2008). Connexons and cell adhesion: a romantic phase. Histochem. Cell Biol. 130, 71-77. doi: 10.1007/s00418-008-0434-7

Prochnow, N., Hoffmann, S., Vroman, R., Klooster, J., Bunse, S., Kamermans, M., et al. (2009). Pannexin 1 in the outer retina of the zebrafish, Danio rerio. Neuroscience 162, 1039-1054. doi: 10.1016/j.neuroscience.2009.04.064

Rash, J. E., Kamasawa, N., Davidson, K. G., Yasumura, T., Pereda, A. E., and Nagy, J. I. (2012). Connexin composition in apposed gap junction hemiplaques revealed by matched double-replica freeze-fracture replica immunogold labeling. J. Membr. Biol. 245, 333-344. doi: 10.1007/s00232-012-9454-2

Rawanduzy, A., Hansen, A., Hansen, T. W., and Nedergaard, M. (1997). Effective reduction of infarct volume by gap junction blockade in a rodent model of stroke. J. Neurosurg. 87, 916-920. doi: 10.3171/jns.1997.87.6.0916

Ray, A., Zoidl, G., Weickert, S., Wahle, P., and Dermietzel, R. (2005). Site-specific and developmental expression of pannexin 1 in the mouse nervous system. Eur. J. Neurosci. 21, 3277-3290. doi: 10.1111/j.1460-9568.2005.04139.x

Risdall, J. E., and Menon, D. K. (2011). Traumatic brain injury. Philos. Trans. R. Soc. Lond B Biol. Sci. 366, 241-250. doi: 10.1098/rstb.2010.0230

Romanov, R. A., Rogachevskaja, O. A., Bystrova, M. F., Jiang, P., Margolskee, R. F., and Kolesnikov, S. S. (2007). Afferent neurotransmission mediated by hemichannels in mammalian taste cells. EMBO J. 26, 657-667. doi: 10.1038/sj.emboj.7601526

Rouach, N., Avignone, E., Meme, W., Koulakoff, A., Venance, L., Blomstrand, F. et al. (2002). Gap junctions and connexin expression in the normal and pathological central nervous system. Biol. Cell 94, 457-475. doi: 10.1016/S02484900(02)00016-3

Saez, J. C., Schalper, K. A., Retamal, M. A., Orellana, J. A., Shoji, K. F., and Bennett, M. V. (2010). Cell membrane permeabilization via Connexin hemichannels in living and dying cells. Exp. Cell Res. 316, 2377-2389. doi: 10.1016/j.yexcr.2010.05.026

Schock, S. C., Leblanc, D., Hakim, A. M., and Thompson, C. S. (2008). ATP release by way of Connexin 36 hemichannels mediates ischemic tolerance in vitro. Biochem. Biophys. Res. Commun. 368, 138-144. doi: 10.1016/j.bbrc.2008. 01.054

Selvarajah, S., Hammond, E., Haider, A. H., Abularrage, C. J., Becker, D., Hyder, O., et al. (2013). The burden of acute traumatic spinal cord injury among adults in the united states: an update. J. Neurotrauma. 31, 228-238. doi: 10.1089/neu. 2013.3098

Tatsumi, K., Haga, S., Matsuyoshi, H., Inoue, M., Manabe, T., Makinodan, M., et al. (2005). Characterization of cells with proliferative activity after a brain injury. Neurochem. Int. 46, 381-389. doi: 10.1016/j.neuint.2004.12.007

Teubner, B., Odermatt, B., Guldenagel, M., Sohl, G., Degen, J., Bukauskas, F., et al. (2001). Functional expression of the new gap junction gene Connexin47 transcribed in mouse brain and spinal cord neurons. J. Neurosci. 21, 1117-1126.

Thompson, R. J., Jackson, M. F., Olah, M. E., Rungta, R. L., Hines, D. J., Beazely, M. A., et al. (2008). Activation of pannexin-1 hemichannels augments aberrant bursting in the hippocampus. Science 322, 1555-1559. doi: 10.1126/science. 1165209

Unterberg, A. W., Stover, J., Kress, B., and Kiening, K. L. (2004). Edema and brain trauma. Neuroscience 129, 1021-1029. doi: 10.1016/j.neuroscience.2004.06.046 
Venance, L., Rozov, A., Blatow, M., Burnashev, N., Feldmeyer, D., and Monyer, H. (2000). Connexin expression in electrically coupled postnatal rat brain neurons. Proc. Natl. Acad. Sci. U.S.A. 97, 10260-10265. doi: 10.1073/pnas.160037097

Wang, K. K., Larner, S. F., Robinson, G., and Hayes, R. L. (2006). Neuroprotection targets after traumatic brain injury. Curr. Opin. Neurol. 19, 514-519. doi: 10.1097/WCO.0b013e3280102b10

Wang, X., Arcuino, G., Takano, T., Lin, J., Peng, W. G., Wan, P., et al. (2004). P2X7 receptor inhibition improves recovery after spinal cord injury. Nat. Med. 10, 821-827. doi: $10.1038 / \mathrm{nm} 1082$

Wang, Y., Song, J. H., Denisova, J. V., Park, W. M., Fontes, J. D., and Belousov, A. B. (2012). Neuronal gap junction coupling is regulated by glutamate and plays critical role in cell death during neuronal injury. J. Neurosci. 32, 713-725. doi: 10.1523/JNEUROSCI.3872-11.2012

Wennersten, A., Holmin, S., and Mathiesen, T. (2003). Characterization of Bax and Bcl-2 in apoptosis after experimental traumatic brain injury in the rat. Acta Neuropathol. 105, 281-288. doi: 10.1007/s00401-002-0649-y

Wolf, S. J., Bebarta, V. S., Bonnett, C. J., Pons, P. T., and Cantrill, S. V. (2009). Blast injuries. Lancet 374, 405-415. doi: 10.1016/S0140-6736(09)60257-9

Wong, M., and Yamada, K. A. (2001). Developmental characteristics of epileptiform activity in immature rat neocortex: a comparison of four in vitro seizure models. Brain Res. Dev. Brain. Res. 128, 113-120. doi: 10.1016/S01653806(01)00149-3

Wu, X., Hu, J., Zhuo, L., Fu, C., Hui, G., Wang, Y., et al. (2008). Epidemiology of traumatic brain injury in eastern China, 2004: a prospective large case study. J. Trauma 64, 1313-1319. doi: 10.1097/TA.0b013e318165c803

Yong-Ming, Z., Jia-Chuan, L., Yan-Yan, Y., Wen-Jiang, S., Hong, T., Bing-Cang, L., et al. (2012). Effective protection of rabbits' explosive brain injury through blocking gap junction communication. Afr. Health Sci. 12, 552-556.
Yu, B., Ma, H., Kong, L., Shi, Y., and Liu, Y. (2013). Enhanced Connexin 43 expression following neural stem cell transplantation in a rat model of traumatic brain injury. Arch. Med. Sci. 9, 132-138. doi: 10.5114/aoms.2012. 31438

Zhao, X., Ahram, A., Berman, R. F., Muizelaar, J. P., and Lyeth, B. G. (2003). Early loss of astrocytes after experimental traumatic brain injury. Glia 44, 140-152. doi: 10.1002/glia.10283

Zoidl, G., Petrasch-Parwez, E., Ray, A., Meier, C., Bunse, S., Habbes, H. W., et al. (2007). Localization of the pannexin1 protein at postsynaptic sites in the cerebral cortex and hippocampus. Neuroscience 146, 9-16. doi: 10.1016/j. neuroscience.2007.01.061

Conflict of Interest Statement: The author declares that the research was conducted in the absence of any commercial or financial relationships that could be construed as a potential conflict of interest.

Received: 15 November 2013; accepted: 15 January 2014; published online: 11 February 2014.

Citation: Prochnow N (2014) Relevance of gap junctions and large pore channels in traumatic brain injury. Front. Physiol. 5:31. doi: 10.3389/fphys.2014.00031

This article was submitted to Membrane Physiology and Membrane Biophysics, a section of the journal Frontiers in Physiology.

Copyright (C) 2014 Prochnow. This is an open-access article distributed under the terms of the Creative Commons Attribution License (CC BY). The use, distribution or reproduction in other forums is permitted, provided the original author(s) or licensor are credited and that the original publication in this journal is cited, in accordance with accepted academic practice. No use, distribution or reproduction is permitted which does not comply with these terms. 